\title{
Correlation with Age, Sex and Histo-Pathological Spectrum of Appendicular Lesions
}

\section{IJCRR}

Section: Healthcare

Sci. Journal Impact

Factor: 6.1 (2018)

ICV: 90.90 (2018)

\section{R. K. Chandrakar ${ }^{1}$, Reena Banerjee ${ }^{2}$}

${ }^{1,2}$ Associate Professor, Department of Pathology, Chandulal Chandrakar Memorial Medical College, Kachandur, Durg, Chhattisgarh, India.

Background: Appendicitis is one of the most usual abdominal conditions requiring urgent surgical intervention. The current study was done to discover diverse appendicular histopathological lesions, their statistics and the percentage of a ruptured appendix, incidental appendectomy and negative appendectomy.

Type of study: Retrospective cross-sectional study. Materials and Methods: Resected samples of appendices were given to histopathology Department of Pathology Chandulal Chandrakar Memorial Medical College and hospital.

Results: Out of 1180 samples of the appendix, appendicitis accounted for $90.68 \%$ with peak age incidence in the age group of 15 to 25 yrs in both genders. Histopathological diagnoses of different types of appendicitis included acute (49.06\%), acute suppurative $(22.06 \%)$, gangrenous $(17.66 \%)$, perforated $(3.64 \%)$, resolving/ recurrent chronic $(2.90 \%)$, acute eosinophilic $(3.46 \%)$, xantho-granulomatous $(0.84 \%)$, and carcinoid tumcurrent $(0.37 \%)$. Other important accompanying pathologies were parasitic infestation and Meckel's diverticulosis. Negative appendectomy rate was $7.8 \%$ which was much more common in females.

Conclusion: Incidence of appendicitis is higher in adolescents and young adults and slightly higher in females. Negative appendectomy is also very common in females. Last but not the least, an unusual finding such as carcinoid tumour in the clinically suspected acute appendicitis reflects the value of histological examination of every resected appendix and its presence would change the currents of further management.

Key Words: Appendicitis, Histo-pathology, Carcinoid Tumcurrent

\section{INTRODUCTION}

There is a long list of surgical causes of acute pain in the abdomen like appendicitis, bowel obstruction, cholecystitis, pancreatitis, ureteric obstruction, rupture of splenic artery aneurysm and among them; acute appendicitis is one of the most common cause. Appendicitis commonly occurs among young adults and adolescents with the lifetime risk of around $7 \%$ but its rate is variable worldwide. The yearly appendicitis incidence rate in different parts of the United States of America from 1979 to 1984 varied from 94 to 154 per $100,000^{1}$. In the United Kingdom, at University Hospital of North Tees, the incidence of acute appendicitis reduced from about 100 to 52 per one lakh population from 1975 to $1991 .{ }^{1,2}$

Due to the promotion of the western diet, the incidence is increasing in most of the urban population in developing countries ${ }^{3}$. Irrespective of advances in imaging modalities and overall medical technology, still there is the predicament in the clinical diagnosis of acute appendicitis till now. Hence the gold standard method for the confirmation of the appendicitis is Histopathological examination till now. Pathological diagnosis of acute inflammation is of paramount importance, but occasionally atypical findings such as incidental tumours detected in the appendix show us the importance of the pathological examination of every single resected appendix. The current study aims to determine the various histological diagnoses of all appendices removed during surgeries and to find out the incidence of appendicitis with age and sex. Also, the current study will emphasize the determination of the rate of negative and incidental appendectomies and perforation rate. Additionally, we will seek to find out the most probable causes of negative appendectomy.

\section{Corresponding Author:}

Dr. Reena Banerjee, Associate Professor, Department of Pathology, Chandulal Chandrakar Memorial Medical College, Kachandur, Durg, Chhattisgarh, 490024; Email: ambad.sawan@gmail.com

ISSN: 2231-2196 (Print)

Received: 20.05 .2020
ISSN: $0975-5241$ (Online)

Revised: 18.06 .2020
Accepted: 08.07 .2020 


\section{MATERIALS AND METHODS}

This was a retrospective study conducted in the Department of Pathology at Chandulal Chandrakar Memorial medical college and hospital. All the surgically resected samples of appendices were sent to the department of pathology were included in this study. All emergency and interval appendectomies performed on clinically suspected appendicitis, and incidental appendectomies which were performed during other abdominal or pelvic surgeries were included. Pertinent clinical data and histopathological diagnoses were recovered from pathology records and computer databases. Statistical analysis was done by SPSS V27. Appendectomy performed for a clinical diagnosis of acute appendicitis but in which the appendix was found to be normal on histo-pathological examination was called Negative Appendectomy.

\section{OBSERVATIONS AND RESULTS}

Table 1: Sex wise Distribution of Histo-pathological types of appendicitis

\begin{tabular}{|c|c|c|c|}
\hline Histological types of appendicitis & Female $(n=560)$ & Male $(n=510)$ & Total $(\mathrm{n}=1070)$ \\
\hline Acute & $280(50 \%)$ & $245(48.04 \%)$ & $525(49.06 \%)$ \\
\hline Acute suppurative & $108(19.29 \%)$ & $128(25.09 \%)$ & $236(22.06 \%)$ \\
\hline Acute gangrenous & $91(16.25 \%)$ & $98(19.21 \%)$ & $189(17.66 \%)$ \\
\hline Perforated & $30(5 \cdot 36 \%)$ & $9(1.76 \%)$ & $39(3.64 \%)$ \\
\hline Eosinophilic & $28(5 \%)$ & $9(1.76 \%)$ & $37(3.46 \%)$ \\
\hline Chronic/ resolving/recurrent & $18(3.21 \%)$ & $13(2.54 \%)$ & $31(2.90 \%)$ \\
\hline Xanthogranulomatous & $5(0.89 \%)$ & $4(0.78 \%)$ & $9(0.84 \%)$ \\
\hline With Carcinoid tumor & o $(0 \%)$ & $4(0.78 \%)$ & $4(0.37 \%)$ \\
\hline
\end{tabular}

Table 2: Negative appendectomy showing other pathologic diagnoses

Periappendicitis

Twisted ovarian cyst

7

Haemorrhagic endometriotic cyst with periappendicitis

5

Meckel's diverticulitis

Follicular cyst
Table no 1 and 2 showed Overall 1180 samples of the appendix were received in the department of histopathology for 2 years. Of the total 1180 appendectomies, there were 1089 cases of emergency appendectomy and 45 cases of interval appendectomy which were performed for suspected cases of appendicitis (1134 cases) on clinical examination. The remaining 46 cases were elective or incidental appendectomy which was done for other pelvic or abdominal pathology. On histopathological examination, total $1070(90.68 \%)$ cases of appendicitis were confirmed. Among 1070 cases of appendicitis, there were $510(43.22 \%)$ males and $560(47.46 \%)$ females with the male: female ratio of 1:1.1. Incidence was at its peak for males at 15 to 20 years and 25 to 30 years for females.

Maximum cases of appendicitis ( $>80 \%)$ occurred below the age of 40 years. Chronic/ recurrent/ resolving and eosinophilic appendicitis were commonly seen in the age group of 25 to 35 yrs. Table 1 shows the sex-wise distribution of inflamed appendices which are at various stages. Rate of Perforation was $3.64 \%$ ( 39 out of 1070 cases). Females in the age group of 15-25 yrs more commonly showed perforated appendici- tis. The parasite was present in 2 histologically proven cases of appendicitis. In four patients (all males) who are clinically suspected as appendicitis, Carcinoid tumour was diagnosed incidentally. The tumour was found at the appendicular apex of $1.2 \mathrm{~cm}$ length with no metastasis and hence the patient was kept under strict follow up without further surgical intervention. The rate of negative appendectomies was 7.8\% (92 out of 1180 cases).

It was appreciably higher in female cases and the age group of 25-30 years with male: female ratio of 1:3. Table 2 shows some Primary causes of acute abdominal pain which was found in a few negative appendectomies. Eight males and 38 females, a total of 46 cases $(3.90 \%)$ had an incidental appendectomy. The primary surgery most commonly done was total abdominal hysterectomy with salpingo-oophorectomy (30 cases) on both sides followed by oophorectomy (4 cases), GI surgery (10 cases; 2 females, 8 males) and two females for emergency exploratory laparotomy. Out of 24 cases were histologically diagnosed as acute appendicitis; 18 were females and 6 were males. 


\section{DISCUSSION}

For several decades, the most common surgical emergency remained acute appendicitis and appendectomy is by far the most commonly performed abdominal surgical intervention. Acute appendicitis amounts for approximately $40 \%$ of all emergency surgical interventions in the western world. Compared to European countries, it is infrequent in African and Asian subcontinent; but recent scientific studies showed a rise in the incidence of appendicitis due to adoption of western diet and lifestyle..$^{3-5}$

The other studies showed a varying incidence of appendicitis. Khan et al. ${ }^{6}$, reported that acute appendicitis as the commonest cause of emergency laparotomy with an incidence of $26 \%$. However, the research conducted by Makaju et al. ${ }^{7}$, there was a downward incidence of acute appendicitis of only $7.46 \%$. Incidence of appendicitis was higher in the $2^{\text {nd }}$ and $3^{\text {rd }}$ decade and around $80 \%$ cases of appendicitis occurred below 40 years of age which is in agreement with numerous other researches. ${ }^{3,8,9}$

Contrary to other studies ${ }^{3,4,9}$ that showed the ratio of male to female ranging from 1 to $3: 1$, we had slightly female predominance with the female is to male ratio of 1.1:1. However, it was observed that adolescent males had a higher incidence than females which is in agreement with other studies. Maximum cases of histological diagnoses were acute appendicitis (49.06\%). Other study done by Zulfikar et al..$^{10}$ and Nabipcurrent et al. ${ }^{9}$ found a loose positive association between the histological staging and demography. In the current study, age incidence followed a somewhat same pattern in all cases of acute appendicitis occurring in young adults. Eosinophilic appendicitis and chronic appendicitis were more common in slightly older females.

The incidence of eosinophilic appendicitis was $3.46 \%$ in the current study which was proximate to the incidence of $1 \%$, found by Park et al. ${ }^{11}$ The diagnosis of chronic appendicitis is still disputable; and its reality has been arguable. Some authors hypothesized that chronic pain in the pelvis to some extent, associated with chronic appendicitis when eliminated from an anatomically normal pelvis, can decrease pain in $50 \%$ of the cases. ${ }^{12,13}$ In the current study, it was diagnosed to be $2.90 \%$ in the young and older individuals, while it was on the higher side in another study ${ }^{13}$. Therefore, repeated and periodic abdominal pain must never be ignored and a higher scepticism of appendicitis is necessary to avoid persistent and unwanted admissions. The rate of perforation was less $(3.64 \%)$ in the current study which is similar to other studies. ${ }^{9,14}$ Few of other similar studies ${ }^{2,4,8,15}$ nevertheless had greater values, ranging from $8 \%$ to $25 \%$.

Parasitic infestation is concluded to be one of the causes of obstruction of the appendicular lumen which in turn leads to appendicitis. Numerous studies have found the parasite in the appendicular lumen to be associated with or without appendicitis in the range of 0.3 to $3.5 \%{ }^{15,16}$. Most common parasites associated includes Enterobius Vermicularis, Schistosoma Sp, Taenia Sp and Ascaris Lumbricoides. There were four cases of incidental carcinoid tumcurrent $(0.37 \%)$. Studies $^{12,14,16-18}$ showed the incidence of carcinoid tumour ranging from $0.1 \%$ to $1.5 \%$, mostly found accidentally during microscopic examination.

In the current study, negative appendectomy was seen in 7.8 $\%$ cases. Various previous studies ${ }^{9,10,14,16}$ have shown a broad spectrum of rate which falls between 6 to $35 \%$, with a higher percentage in women. The present study showed women having a higher percentage of negative appendectomy usually occurring within the range of 15 to $25 \mathrm{yrs}$. Edino et. al. and Marudanayagam et $\mathrm{al}^{14}$ showed a higher incidence in the age group of 10- $30 \mathrm{yrs}$ on an average. Like other studies ${ }^{14,15,19}$ we found other pathological conditions like Periappendicitis, Twisted ovarian cyst, Haemorrhagic endometriotic cyst with periappendicitis, Meckel's diverticulitis and Follicular cyst as the causes of acute pain in the abdomen in negative appendectomy. Hence in women, other causes of pain in the abdomen should be looked for if the appendix looks to be normal during operation. Most of the negative appendectomy cases get relieved of pain after surgery. Wang et $\mathrm{al}^{20}$ showed that TNF- $\alpha$ and interleukin-2 expression are potent markers of appendicular inflammation.

The rate of an incidental appendectomy was only $3.9 \%$ in the current study. Similar to other studies ${ }^{16}$, incidental appendectomy was much more common in women undergoing surgical intervention of pelvis above the age of 30 years. Authors have recommended for incidental appendectomy in all abdominal or pelvic surgeries. ${ }^{12,18,20}$ Such routine of incidental appendectomy in the uncomplicated abdominal or pelvic surgery will reduce the percentage of mortality as well as morbidity associated with appendicitis and related surgical interventions in the elderly patients ${ }^{21}$.

\section{CONCLUSION}

Current study strongly concludes that there is a higher incidence of appendicitis in $2^{\text {nd }}$ and $3^{\text {rd }}$ decades of life and comparatively greater chances in women. Low rate of perforation indicates a better future for patients of appendicitis regarding their clinical outcome. Findings of pelvic pathologies in female patients with negative appendectomy accentuate the effectiveness of the laparoscopy. An incidental appendectomy may have a prophylactic advantage in elderly women. At last, an uncommon finding like carcinoid tumour in the clinically suspected case of acute appendicitis shows us the value of histopathological examination of every recovered appendix, the presence of such finding will significantly alter the future course of clinical management. 
Acknowledgement: Authors acknowledge the immense help received from the scholars whose articles are cited and included in references of this manuscript. The authors are also grateful to authors / editors / publishers of all those articles, journals and books from where the literature for this article has been reviewed and discussed.

\section{Conflict of Interest: Nil}

\section{Source of Funding: Nil}

\section{REFERENCES}

1. Walker et al. Appendicitis: an African perspective. J R Soc Med 1995; 88:616-9.

2. Al-Omran $\mathrm{M}$ et al. Epidemiologic features of acute appendicitis in Ontario, Canada. Can J Surg 2003;46:263-8.

3. Oguntola A et al. Appendicitis: Trends in incidence, age, sex, and seasonal variations in South-Western Nigeria. Ann Afr Med 2010;9:213-7.

4. Edino $\mathrm{S}$ et al. Appendicitis in Kano, Nigeria: A 5 years review of the pattern, morbidity and mortality. Ann Afr Med 2004;3:3841.

5. Malay Kumar Barman, Kaustav Das, Koel Mukherjee. A Study on Comparision of Diagnostic Efficiency between Modified Alvarado Score and Graded Compression Ultrasonography in the Case of Acute Appendicitis International Journal of Current Research and Review. Vol 10 Issue 09, May, 22-26.

6. Khan et al. Retrospective analysis of abdominal surgeries at Nepalgunj Medical College (NGMC), Nepalgunj, Nepal: 2 year's experience. KUMJ 2004;2:336-43.

7. Makalu R et al. Acute appendicitis: Analysis of 518 histopathologically diagnosed cases at the Kathmandu University Hospital, Nepal. KUMJ 2010;8:227-30.

8. Noudeh Y et al. Epidemiologic features, seasonal variations and false positive rate of acute appendicitis in Shahr-e-Rey, Tehran. Int J Surg 2007;5:95-8.
9. Nabipcurrent F. Histo-pathological feature of acute appendicitis in Kerman-Iran from 1997 to 2003. Am J Env Sci 2005;1:130-2.

10. Park $\mathrm{C}$ et al. Pathologic analysis of 2159 cases of appendix. Korean J Pathol 2000;34:39-49.

11. Salom E et al. The safety of incidental appendectomy at the time of abdominal hysterectomy. Am J Obstet Gynecol 2003; 189:1563-7

12. Chang S, Chan P. Recurrent appendicitis as a cause of recurrent right iliac fossa pain. Singapore Med J 2004;45:6-8.

13. Korner $\mathrm{H}$ et al. Incidence of acute nonperforated and perforated appendicitis: Agespecific and sexspecific analysis. World J. Surg 1997;21:313-7.

14. Marudanayagam $\mathrm{R}$ et al. Review of the pathological results of 2660 appendicectomy specimens. J Gastroenterol 2006;41:7459.

15. Duzgun A et al. Unusual findings in appendectomy specimens: Evaluation of 2458 cases and review of the literature. Indian $\mathrm{J}$ Surg 2004;66:221-6.

16. Ojo $\mathrm{O}$ et al. Review of the histo-pathological findings in appendices removed for acute appendicitis in Nigerians. J R Coll Surg Edinb 1991;36:245-8.

17. Jones A et al. The value of routine histo-pathological examination of appendicectomy specimens. BMC Surg 2007;10:7.

18. Engin $\mathrm{O}$ et al. Gynecologic pathologies in current appendectomy series and literature review. J Korean Surg Soc 2011;80:26771.

19. Snehal Deshmukh, Mugdha L Jungari, Urvashi Shrama. Use of PG-E 2 Gel for Cervical Ripening in Labour Induction International Journal of Current Research and Review. Modern Therapeutics Applications, July, 2020, 110-113.

20. Wang $Y$ et al. Is a histologically normal appendix following emergency appendicectomy always normal? Lancet 1996;20:1076-9.

21. Anamul Haq, Sheema, Shazieya Akhtar. Etiology of Abnormal Uterine Bleeding in Adolescents - Emphasis Upon Polycystic Ovarian Syndrome International Journal of Current Research and Review. 2020; Vol 12 Issue 10, May, 05-09. 